\title{
EVALUATION OF MICROLEAKAGE AND MICROTENSILE BOND STRENGTH OF TWO BULK FILL COMPOSITES IN PRIMARY TEETH AFTER CARIES REMOVAL BY CHEMOMECHANICAL TECHNIQUE.
}

\author{
Fatma Mohamed Mostafa Elsaied Elhendawi ${ }^{1}$, Mohamed Sherif Mohamed Sallah Eldeen ${ }^{2}$, \\ Wael Mahmoud Abd Al Khalek Mohamed ${ }^{3}$, Shereef Samy Abdellateef ${ }^{4}$
}

DOI: $10.21608 / d s u .2020 .22350 .1020$

Manuscript ID: DSU-2001-1020

\section{KEYWORDS}

Bulk fill composite,

Caries removal,

Chemo-mechanical,

Papacarie.

- E-mail address: hesham.mohammed86@yahoo.com

1. B.D.S Mansoura University (2010), General dental practitioner in the Ministry of Health

2. Professor and head of Pediatric and Preventive Dentistry and Dental Public Health, Faculty of Dentistry, Suez Canal University.

3. Assistant Prof. of Pediatric and Preventive Dentistry and Dental Public Health, Faculty of Dentistry, Zagazig University

4. Lecturer of Pediatric and Preventive Dentistry and Dental Public Health, Faculty of Dentistry, Suez Canal University

\begin{abstract}
Introduction: Evaluation of Microleakage and Microtensile Bond Strength of Two Bulk Fill Composites in Primary Teeth after Caries Removal by Chemomechanical Technique. Aim: to evaluate microleakage as well as microtensile bond strength of two bulk fill composites (X-tra fill packable and X-tra base flowable bulk fill composites) in primary teeth after chemomechanical caries removal. Material and methods: forty extracted human carious primary posterior teeth without pulp exposure were assigned after caries removal by Papacarié into two groups based on restorative material used, each containing 20 teeth. Group 1: was restored with X-tra fill. Group 2: was restored with X-tra base. In two groups Futurabond dual-curing self-etch bond was used to bond restorations to the dentin. The two groups were subdivided into 2 subgroups: Sub-group A: 10 teeth used for microleakage test. Sub-group B: 10 teeth used for microtensile bond strength test. For microleakage test: After thermocycling; teeth were covered with varnish then immersed in $2 \%$ methylene blue for $24 \mathrm{~h}$., thereafter the dye penetration was assessed with measured in micrometer using MA100 fully configured Halogen inverted scope. For microtensile test: The specimens were sectioned longitudinally to the tooth long axis for obtaining sticks of standardized cross sectional region. Such sticks were stressed to failure using tensile force in a universal testing machine. The $\mu$ TBs for each sample was calculated in megapascal. Results: X-tra Fill showed lower insignificant mean microleakage compared to $\mathrm{X}$-tra Base at $\mathrm{P}$ value $=0.3$. X-tra Fill showed higher insignificant mean $\mu \mathrm{TBs}$ (MPa) compared to $\mathrm{X}$-tra Base at $\mathrm{P}$ value $=0.097$. Conclusion: Both bulk fill composites have performed approximately similar regarding microleakage and $\mu \mathrm{TBs}$ after using Papacarie for caries removal.
\end{abstract}

\section{INTRODUCTION}

Every dentist interest is to preserve a healthy set of natural teeth for each patient. The aim of any work in the health field is basically to preserve the body of human and its function ${ }^{(\mathbf{1})}$. Dental caries is a serious public health problem that when not treated the disease can result in tooth loss, pain, infection and pulp death in severe cases. It can also lead to malocclusion, speech problems and lack of self-respect. Pediatricians and pediatric dentists alike are concerned about issue of dental caries in infants and young adults ${ }^{(2)}$. Classical ways for preparation of cavity is based on a philosophy of extension for prevention. However, drilling frequently removes tooth parts that are healthy, along with the decayed 
areas. This makes the tooth weak and less durable in the long run ${ }^{(3)}$. The known barriers for the receptivity of dental treatment affecting oral health are anxiety and fear. The conventional drilling methods cause discomfort, particularly in children ${ }^{(4)}$. Chemo-mechanical is a non-invasive method for removal of caries through removing infected dentin by a chemical agent. This mechanism eliminates infected tissues, and in addition preserves healthy dental structure ${ }^{(5)}$. In Brazil, a study conducted in 2003 cause developing of a new formula to universalize utilizing of chemo-mechanical technique for removal of caries and encourage using it in public health. The new formula of papain based gel was commercially known as Papacarie ${ }^{(6)}$. Restoration of cavities prepared by this method needs materials like glass ionomer or composite resins that attach to the dentin surface more than materials like amalgam that involve cutting a cavity designed to mechanically retain the restoration ${ }^{(5)}$. Manufacturers of composite materials, aimed to simplify the technique to introduce the material into the cavity and its polymerization, now offer bulkfill type composite resins. Procedures simplification and lowering the time of embedding bulk-fill type restorations are because of probability of applying a single up to $4 \mathrm{~mm}$ composite increment and this quick the work through lowering the clinical steps number. The innovative system of initiating polymerization determines lowering time of light and elevating the cure depth. Reduce these materials shrinkage and elevate filler content causes lowering to shrinkage stresses which permits for application of thicker layers. The color matching process time is decreased because of universal color of materials and shorter time of finishing and polishing of the restoration was remarked ${ }^{(7,8)}$. There are two types of bulk fill composite packable and flowable bulk fill composite, therefore this investigation will be conducted to compare packable bulk fill composite versus the flowable in regard to microleakage and microtensile bond strength in primary teeth following removal of caries by chemomechanical technique.

\section{MATERIALS AND METHODS}

\section{Materials:}

1) Forty extracted human carious primary posterior teeth without pulp exposure. 2) Papain-based gel to removal of caries through chemo-mechanical (Papacarie,F\&A Laboratório Farmacéutico Ltda, São Paulo, Brazil). 3) Restorative materials: (a) Xtra fill, packable posterior bulk fill composite. (b) X-tra base, flowable posterior bulk fill composite. (c) One adhesive system: Futurabond ${ }^{\circledR} \mathbf{D C}^{*}$ dualcured, self-etching bonding agent supplied in Single Dose blister packs. The system composed of 2 liquids: the dual-cured activator and the self-etching bonding agent. To activate the blister pack, it was pressed to permit mixing of both liquids. Puncture the foil by the brush of applicator and stirring then it was applied to the tooth for 20 seconds, air dried for 5 seconds and light cured for 10 seconds by the use of LED light curing unit (MontixLiteQ LD_107) ${ }^{*, * *}$ as manufacturer's instructions.

\section{Methods:}

\subsection{Selection criteria of teeth:}

Inclusion criteria: 1-Teeth were extracted because of normal shedding or orthodontic reasons. 2- Caries wasn't involving pulp exposure.

\footnotetext{
* Futurabond DC: Voco GmbH, Cuxhaven, Germany

** Monitex industrial Co., Ltd, Taiwan.
} 
3- The diameter of cavity openings $\geq 2 \mathrm{~mm}$, and have accessibility to instruments of the hand. Exclusion criteria: Any tooth showing signs of extraction damage as crown fracture and enamel chipping All teeth were cleaned under tap water, disinfected in $2 \%$ sodium hypochlorite, and then were kept in saline solution $0.9 \%$ at temperature of the room until the time of filling.

\subsection{Caries removal:}

Based on the instructions of the manufacturer, the carious lesions were filled with the Papacarié. Following 30 seconds, the gel directly became turbid with debris; softened carious dentin was scraped away through utilizing a spoon excavator opposite side in a pendulum movement. The gel was reapplied if remaining caries was still present. (9) Between the applications the cavities were not washed or dried. Following complete removal of caries, as decided via the clinical criteria (visual inspection and probing), removing the gel by a cotton pellet immersed in water. The appearance of cavities was vitreous. ${ }^{(9)}$

\subsection{Grouping:}

Randomly, teeth were classified into 2 groups (20 for every group) based on restorative material utilized.

Group I: was restored with X-tra fill, packable posterior bulk fill composite.

Group II: was restored with X-tra base, flowable posterior bulk fill composite.

Futurabond dual-curing self-etch bond was added in both groups to bond restorations to the dentin. All materials were manipulated based on the instructions of manufacturer. Every group was subdivided into 2 subgroups (10 for each subgroup).
Subgroup A: 10 teeth used for microleakage test.

Subgroup B: 10 teeth used for microtensile bond strength test.

\subsection{Restorative Procedures:}

All materials were used based on the instructions of manufacturer.

Adhesive (Futurabond ${ }^{\circledR} \mathrm{DC}$ ) was applied as mentioned formerly.

Group1: X-tra Fill, bulk fill composite was used to restore the cavities. The restoration technique involved placing one increment of $4 \mathrm{~mm}$ for the cavity after that the composite was light cured for $10 \mathrm{sec}$ by the use of LED light curing unit (MonitexLiteQ LD-107) at 1000mW/ $\mathrm{cm}^{2}$. Group 2: $\mathrm{X}$-tra Base, bulk fill composite was used to restore the cavities. The restoration technique involved placing one increment of $4 \mathrm{~mm}$ for the cavity then the composite was light cured for $10 \mathrm{sec}$ by the use of LED light curing unit (MontexLiteQ LD-107) at $1000 \mathrm{~mW} / \mathrm{cm}^{2}$.

\subsection{Storage:}

Between all steps of procedures, specimens were kept in normal saline $0.9 \%$ solution at room temperature.

\subsection{Microleakage test:}

2.6.1-Thermocycling regime: all samples were thermo cycled for 500 cycles at a temperature $5^{\circ} \mathrm{C}$ and $55^{\circ} \mathrm{C}$, with dwell time 30 seconds in every bath and at interval five seconds between them (in distilled water). ${ }^{(10)}$

\subsection{2- Preparation prior to sectioning: After that the} teeth were embedded in acrylic resin blocks for facilitating of handling and covered with 
2 layers of nail varnish with exception of 1.0 $\mathrm{mm}$ of the restoration margins, were stored without any coating to avoid leakage of dye through cracks from external surface of the tooth. The coated teeth were submerged in $2 \%$ solution of methylene blue dye for one day. Following removal from the dye, the acetone solution was used to remove the coating and washing the teeth completely under tap water for ten minutes and dab dry by tissue paper.The samples were stored in bottles which contain distilled water till the sectioning time ${ }^{(9)}$.

2.6.3-Sectioning of specimens: this was done longitudinally in the mesiodistal plane at mid line of the restoration. This was achieved through the use of automated diamond saw* with cooling system (Isomet 4000)* The samples were washed under running water and then dried by tissue paper ${ }^{(9)}$.

\subsection{4-Evalution of microleakage: Microleakage} was measured in micrometer using MA100 fully configured Halogen inverted scope at $35 \times$ magnification with software, Omni Met Nikon, Japan.

\subsection{Microtensile Bond Strength:}

2.7.1-Teeth preparation: cylindrical Teflon mold (with diameter of $15-\mathrm{mm}$ and height 40$\mathrm{mm}$ ), with a corresponding metal ring with two opposing screws at its sides was utilized to produce acrylic resin blocks. The screws were used to hold the tooth in place in with centrally position, parallel to the long axis of the mold, within the acrylic resin setting.
Teeth fixed in acrylic resin blocks were then organized in an automated diamond saw (Isomet 4000), that was utilized in all sectioning steps of this research.

2.7.2-Beam preparation: The objective of longitudinal sectioning of restored teeth was to obtain composite-dentin beams of $(0.9 \mathrm{~mm}$. x $0.9 \mathrm{~mm}$.) in area. Each beam was composed of composite and dentin with adhesive at the interface. After mounting the teeth in the Isomt, restored teeth were serially sectioned, by the use of a $0.3-\mathrm{mm}$. thick diamond coated disc, at $2050 \mathrm{rpm} ; 8.8 \mathrm{~mm} / \mathrm{min}$ feeding rate; under copious coolant. Successive sectioning was made in bucco-lingual direction after that rotated $90^{\circ}$ clockwise and sectioned in mesio-distal. A final horizontal cut at level of cemento-enamel junction was done to obtain beams using low speed fine diamond disc attached to micromotor. The thickness of resultant beams were $0.9 \pm 0.1 \mathrm{~mm}$. with a length $5.5 \pm 1 \mathrm{~mm}$. For checking the thickness and length of all beams, a digital caliper was utilized.

2.7.3-Micro-tensile bond strength measurement: For every tested group, 10 beams were tested. A jig was used to mount each beam onto the universal testing machine (Instron) ${ }^{* *}$ with a load cell of $500 \mathrm{~N}$. Tensile load was used, with a cross-head speed of $0.5 \mathrm{~mm} / \mathrm{min}$, till occurring bonding failure of the samples. Microtensile bond strength was measured in MegaPascal. Bond strength was calculated by (Bluehill Lite software). Specimen fragments were strictly removed from the jig with a scalpel to separate them from the glue.

\footnotetext{
* Buehler, USA, www.buehler.com

** Instron, USA, http://www.instron.com/
} 


\subsection{Statistical analysis:}

Descriptive data: Descriptive statistics were measured in the form of:

1. Mean \pm Standard deviation (SD).

2. Range (Minimum -Maximum)

Analytical statistics: In the statistical comparison among the various groups, the importance of variation was tested by the use of Student's $t$-test for comparison between mean of 2 various groups of numerical (parametric) data. The computer program SPSS (Statistical package for social science) version 17.0 used for tabulating, coding then analyzing the data for obtaining a $P$ value $<0.05$, which believed statistically important (S).

\section{RESULTS}

\section{Comparisons between group I \& group II:}

\section{1- Microleakage:}

The present study showed that (Table 1) and (Figure 1) mean miroleakage of packable (X-tra Fill) bulk fill composite is $753.9 \mu \mathrm{m} \pm 348.2 \mu \mathrm{m}$ which is lower than the mean microleakage of flowable (X-tra Base) bulk fill composite 888. $\mu \mathrm{m} \pm 333.5 \mu \mathrm{m}$ with non-statistically significant difference between the 2 groups $(\mathrm{P}$ value $=0.3$ ).

The depths of dye penetration at the tooth restoration interface (shown by MA100 fully configured Halogen inverted scope at $35 \times$ magnification with software, Omni Met Nikon, Japan) is presented in (Figure 2). It is $781.318 \mu \mathrm{m}$ in packable (X-tra Fill) bulk fill resin composite and $969.031 \mu \mathrm{m}$ in flowable (X-tra Base) bulk fill composite.

\section{2- Microtensile bond strength:}

The present study showed that (Table 2) and (Figure 3) mean microtensile bond strength of packable (X-tra Fill) bulk fill composite is 23.98 $\mathrm{MPa} \pm 7.954 \mathrm{MPa}$ which is higher than the mean microtensile bond strength of flowable (X-tra Base) bulk fill composite $17.82 \mathrm{MPa} \pm 7.814 \mathrm{MPa}$ but with non-statistically significant difference between the 2 groups. $(\mathrm{P}$ value $=0.097)$.

Table (1): Comparisons of Microleakage test $(\mu \mathrm{m})$ between Packable (X-tra fill) \& Flowable (X-tra base) bulk fill composites groups.

\begin{tabular}{|c|c|c|c|}
\hline \multirow[b]{2}{*}{$\begin{array}{l}\text { Microleakage } \\
\text { test }(\mu \mathrm{m})\end{array}$} & \multicolumn{2}{|c|}{ Groups } & \multirow[b]{2}{*}{$\mathrm{P}$} \\
\hline & $\begin{array}{c}\text { Group I } \\
\text { Packable } \\
\text { (X-tra fill) }\end{array}$ & $\begin{array}{c}\text { Group II } \\
\text { Flowable } \\
\text { (X-tra base) }\end{array}$ & \\
\hline Mean & 753.9 & 888.9 & \multirow{2}{*}{0.3} \\
\hline$\pm \mathrm{SD}$ & 348.2 & 333.5 & \\
\hline
\end{tabular}

P: Probability *: significance $<0.05$

Test used: Student's t-test

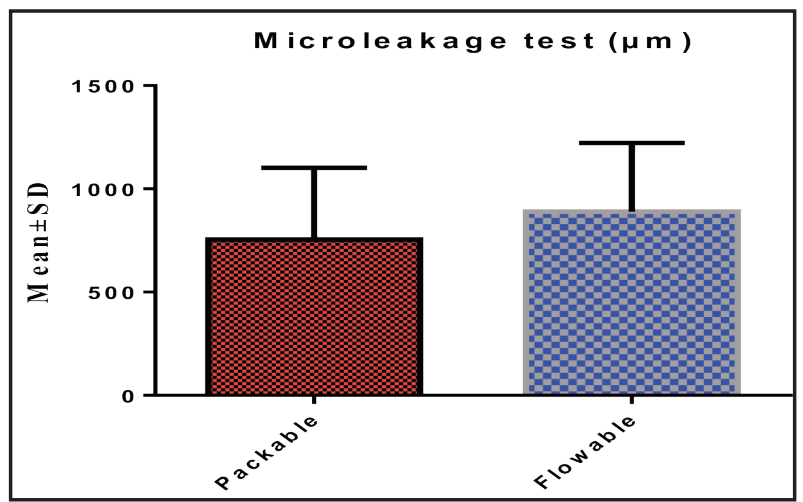

Fig. (1) Mean and standard deviation microleakage of packable (X-tra Fill) and flowable (X-tra Base) bulk fill composites. 


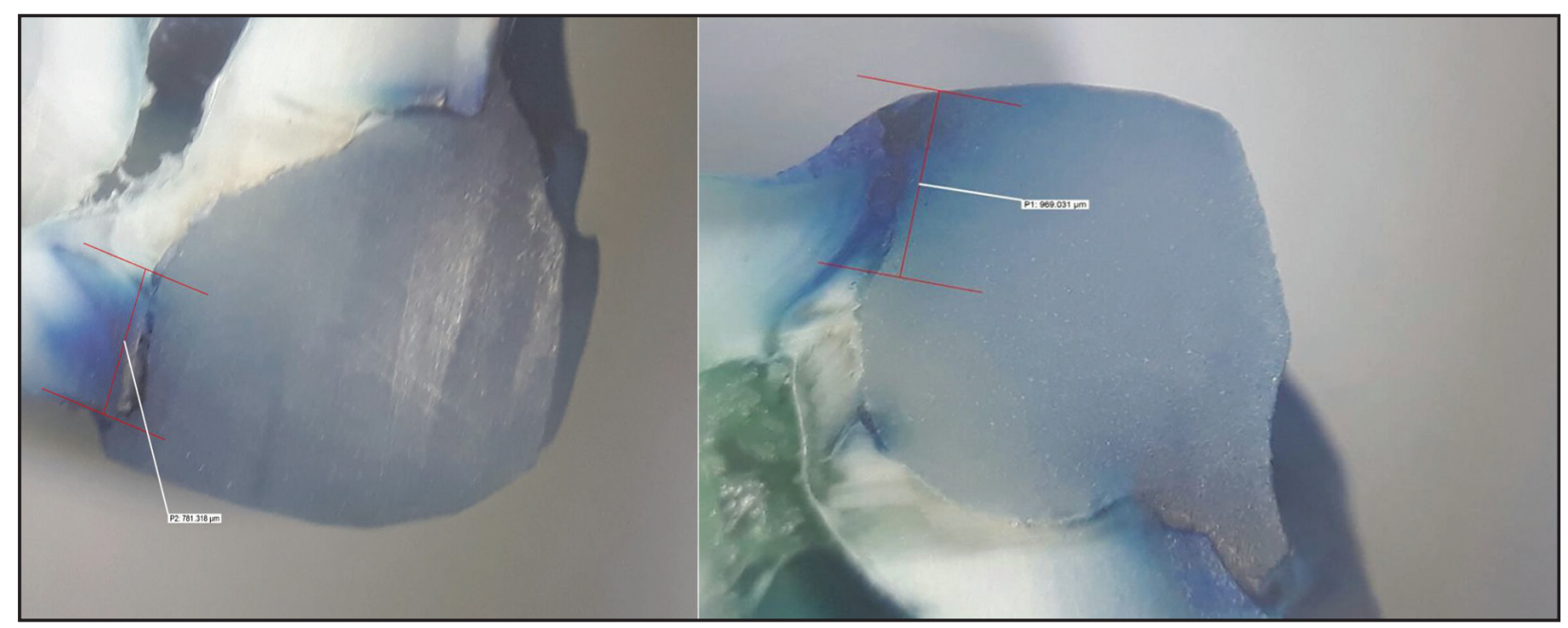

Fig. (2) Depth of dye penetration at the tooth restoration interface A) Packable (X-tra Fill) bulk fill resin composite restoration B) Flowable (X-tra base) bulk fill resin composite restoration.

Table(2): Comparisons of Tensile Stresses at Maximum Load (MPa) between Packable (X-tra fill)\&Flowable (X-tra base) bulk fill composites groups

\begin{tabular}{|c|c|c|c|}
\hline \multirow{2}{*}{$\begin{array}{c}\text { Tensile Stresses at } \\
\text { Maximum Load } \\
(\mathrm{MPa})\end{array}$} & $\begin{array}{c}\text { Group I } \\
\text { Packable } \\
\text { (X-tra fill) }\end{array}$ & $\begin{array}{c}\text { Group II } \\
\text { Flowable } \\
\text { (X-tra base })\end{array}$ & \\
\hline Mean & 23.98 & 17.82 & \multirow{2}{*}{0.097} \\
\hline \pm SD & 7.954 & 7.814 & \\
\hline
\end{tabular}

P: Probability *: significance $<0.05$

Test used: Student's t-test.

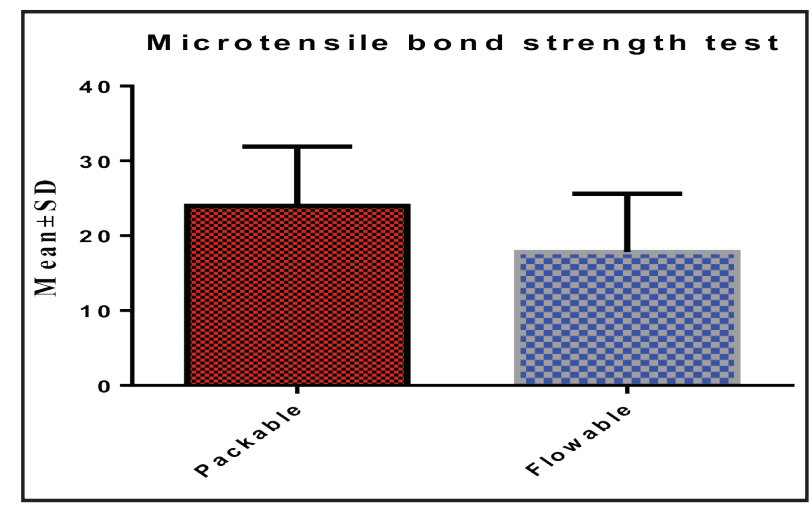

Fig. (3) Mean and standard deviation microtensile bond strength of packable (X-tra fill) and flowable (Xtra base) bulk fill composites.

\section{DISCUSSION}

Papain is a proteolytic enzyme like pepsin, it only acts on infected tissues. Chloramines exist in the product have the possibility to break down carious dentin by chlorination of partly degraded collagen ${ }^{(11)}$.As the result of microleakage and bond strength among the surface of tooth and the restorative material is depend on the features of the surface of remaining dentin. Therefore this research was done to evaluation of microleakage and microtensile bond strength of 2 bulk fill composites (X-tra fill packable bulk fill composite and $\mathrm{X}$-tra base flowable bulk fill composite) in primary teeth following removal of caries through chemo mechanical technique.

\section{1- Microleakage:}

Microleakage can be assessed by scanning electron microscope of dye penetration. Penetration of dye is an in vitro method to investigate marginal leakage over tooth restoration interfaces ${ }^{(12-14)}$. Different tracer dyes are available for micro leakage researches, while there is no important difference in penetration of tracer between them ${ }^{(15)}$. Methylene blue that was used in this study is one 
of the most popular tracers and can be utilized at various concentrations ${ }^{(16,17)}$. Dental restorations are exposed to stable and extreme changes in the environment of mouth, with large variations in $\mathrm{pH}$ and temperature ${ }^{(18,19)}$. Therefore, thermo cycling is a significant step for examining the sealing ability of restorative material ${ }^{(20)}$. Thermo cycling at water baths with a temperature $5^{\circ} \mathrm{C}$ and $55^{\circ} \mathrm{C} \pm 2^{\circ} \mathrm{C}$ with a dwell time of $30 \mathrm{sec}$. for 500 cycles. Such variables appear to be tolerated via oral tissues and are suitable for clinical settings ${ }^{(21)}$. The marginal leakage was measured by the help of image analysis software (Omni Met Nikon, Japan) where the total penetration depth of dye along the restoration-tooth interface was calculated in $\mu \mathrm{m}$. In the present study, results showed that mean miroleakage of packable (X-tra Fill) bulk fill composite is $753.9 \mu \mathrm{m} \pm 348.2$ $\mu \mathrm{m}$ which is lower than the mean microleakage of flowable ( X-tra Base) bulk fill composite $888.9 \mu \mathrm{m}$ $\pm 333.5 \mu \mathrm{m}$ but without significant different among the 2 groups ( $\mathrm{P}$ value $=0.3$ ). These results can be explained by the high filler content in the bulk fill composites which results into low polymerization shrinkage this result is in agreement with Masouras et al ${ }^{(22)}$, Moorthy et $\mathbf{a l}^{(23)}$ and Ilie et al ${ }^{(24)}$. Another reason may be because of the reduced viscosity of packable bulk fill materials through modification of the monomers and adding hydroxyl free BIS-GMA combined with highly branched methacrylates that make them well adapted in one layer. This result is in agreement with Czasch et al ${ }^{(25)}$, Ilie et al ${ }^{(24)}$ and Garcia et $\mathbf{a l}^{(26)}$. Moreover, the lowered viscosity of the bulk fill minimized the shrinkage stress and hence decreased the microleakage. These findings come in agreement with, Benetti et al ${ }^{(27)}$, who reported that however many of the bulk-fill materials showed formation of a gap like to that of the conventional resin composite, two of the low-viscosity bulk-fill resin composites, $x$-tra base $(p=0.005)$ and Venus
Bulk Fill $(\mathrm{p}=0.016)$ made larger gaps ${ }^{(27)}$. While this result come disagreement with, Orłowski et al ${ }^{(28)}$,who reported that bulk fill flowable or sonic activated flowable composite restorations have well sealing margin compared to bulk fill packable composites. This difference may be explained by using different method of caries removal. Papacarie only works on infected tissues without a plasmatic anti-protease called $\alpha 1$-anti-trypisin which suppress proteolysis unhealthy tissues so preservation of the affected (non-infected) layer of dentin ${ }^{(29)}$

\section{2- Microtensile bond strength:}

Evaluation of the bond strength in the present study was carried out using $\mu$ TBS which is a protocol has the ability to discriminate adhesives bonding performance than macrotensile and macroshear tests. Besides, it correlates more accurately with the clinical outcomes than microshear testes ${ }^{(30)}$. Moreover, smaller test samples are 'stronger' than larger ones because of the decreased possibility of existence of critical sized defects. Thus micro-bond strength tests (bond area less than three $\mathrm{mm}^{2}$ ) were developed and higher apparent 'strength' can be calculated with more failures at the interface. For a micro-tensile bond strength testing, various types of samples have been examined that can be classified as; slab (rectangular), hourglass, stick (square), and dumbbell geometries, with cross-sectional shapes which are either square, round or rectangular. The sample geometry has an important effect on stress homogeneity and when concentrations of stress cannot be fully avoided, they must be lowered at least ${ }^{(31)}$. In this study, the specimen was sectioned to obtain sticks as the hourglass sample fails at lower stress comparing with the dumbbell or stick, because of the high stress concentration prompted in the adhesive ${ }^{(32 \& 33)}$. The bonded area of specimens is small stick-shaped, about $0.1 \mathrm{~mm}^{2} \pm 0.1$ which 
is important in producing better stress distribution at the adhesive joint, lowering cohesive failures in tooth substrate or composite ${ }^{(34)}$.In the present study, results showed that mean microtensile bond strength of packable (X-tra Fill) bulk fill composite is 23.98 $\mathrm{MPa} \pm 7.954 \mathrm{MPa}$ which is higher than the mean microtensile bond strength of flowable (X-tra Base) bulk fill composite $17.82 \mathrm{MPa} \pm 7.814 \mathrm{MPa}$ but with no statistically significant difference among the 2 groups. ( $\mathrm{P}$ value $=0.097$ ). These findings agree with Öznurhan et al ${ }^{(35)}$, who reported that there were no significant variations in micro tensile bond strength of this bulk fill materials (SDR, X-tra base flowable bulk fill composites and TetricEvoCeram packable bulk fill composite) to dentin. While they come in partially disagreement with Al-Harbi et al ${ }^{\left({ }^{(6)} \text {, who }\right.}$ found that there is no significant variations in $\mu$ TBS values among bulk fill resin composites (packable and flowable) and incremental composite, however, two bulk fill flowable resin composites (Smart Dentin Replacement flowable bulk fill composite and SonicFill) showed higher $\mu$ TBS than the incremental resin composite. The difference in the materials might explain the variations in the results between studies. In addition, the hybrid layers made to caries-affected dentin by papacarie have more thickness than those of normal dentin, as caries affected dentin is more exposed to the acid etching because of partial demineralization, leading to a deeper demineralized zone formation that is more difficult for resin monomer to pierce to the bottom of the susceptible collagen matrix ${ }^{(37-39)}$.

\section{CONCLUSION}

Both bulk fill composites have performed approximately similar regarding microleakage and microtensile bond strength after using Papacarie for caries removal.

\section{Limitations}

The use of teeth with different cavity configuration affected bond strength as they had a different C-factor (The proportion of bonded to unbonded surface area). High C-factor could negatively influence the adhesive interface. 2) Thermocycling was not enough to simulate the oral cavity conditions so, mechanical loading is an important factor to simulate the masticatory loads applied on the restorations in oral cavity. 3) The use of primary teeth with insufficient dentin thickness (due to it is small size) maximizes the difficulties in measuring the bond strength between dentine and restoration. In this study many primary teeth were excluded due to pulp exposure.

\section{REFERENCES}

1. Rainey JT. Air abrasion: an emerging standard of care in conservative operative dentistry. Dent Clin North Am. 2002; 46(2): 185-209.

2. Ribeiro N, Ribeiro M. Breast -feeding and early childhood caries: a critical review. Pediatr. 2004; 80(5):199-210.

3. Jawa D, Singh S, Somani R, Jaidka S, Sirkar K, Jaidka R. Comparative evaluation of the efficacy of chemomechanical caries removal agent (Papacarie) and conventional method of caries removal. An in vitro study. J Indian Soc Pedod Prevent Dent. 2010; 8(2): 73-77.

4. Stewart J M, Marcus M, Christeen P, Lin W. Comprehensive treatment among dental school patients with high and low anxiety. J Dent Educ. 1994; 58: 697-700.

5. Pires Correa EN. Rodrigues Filho LE, Delgado Rodrigues CM. Evaluation of residual dentin after conventional and chemomechanical caries removal using SEM. J Clin Pediatr Dent. 2008; 32(2):115-120,.

6. Sandra KB. Laura CC, Ana CG. Papain Gel: A new chemo-mechanical caries removal agent. J Clin Pediatr Dent. 2005; 30(20):115-120.

7. Peutzfeldt A, Asmussen E. Determinants of in vitro gap formation of resin composites. J Dent. 2004; 32(2): 109-115. 
8. Cenci M, Demarco F, Carvalho R. Class II composite resin restorations with two polymerization techniques: relationship between microtensile bond strength and marginal leakage. J Dent. 2005; 33 (7): 603-610.

9. Khattab NM, Omar OM . Papain-based gel for chemomechanical caries removal: Influence on microleakage and micro shear bond strength of esthetic restorative materials. J Am Sci. 2012; 8(3): 391-399.

10. Loguercio AD, de Oliveira RJ, Reis A, Miranda Grande $\mathrm{RH}$. In vitro microleakage of packable composites in class 2 restorations. Quint Int. 2004; 35(1):29-34.

11. Maragakis GM, Hahn P, Hellwig E. Chemomechanical caries removal: a comprehensive review of the literature. Int. Dent. J. 2001; 51(4):291-299.

12. Ernst CP, Galler P, Willershausen B, Haller B. Marginal integrity of class V restorations: SEM versus dye penetration. Dent Mater. 2008; 24:319-327.

13. Ghasemi A, Torabzadeh H, Mahdian M, Afkar M, Fazeli A, Akbarzadeh BA. Effect of bonding application time on the microleakage of Class V sandwich restorations. Austral Dent J. 2012; 57:334-338.

14. Kusgoz A, Ulker M, Yesilyurt C, Yoldas OH, Ozil M, Tanriver M. Silorane-based composite. Depth of cure, surface hardness, degree of conversion, and cervical microleakage in Class II cavities. J Esthet Restor Dent. 2011; 23:324-335

15. Heintze SD, Forjanic M, Zellweger G, Antonson SA. Polish ability and wear behavior of resin composite bulk fill materials. AADR Annual Meeting, 2012.

16. Fabianelli A, Sgarra A, Goracci C, Cantoro A, Pollington S, Ferrari M. Microleakage in Class II restorations: Open vs closed centripetal build-up technique. Oper Dent. 2010; 35:308-313.

17. Bedran de Castro AK, Pimenta LA, Amaral CM, Ambrosano GM. Evaluation of microleakage in cervical margins of various posterior restorative systems. J Esthet and Restor Dent. 2002; 14:107-114.

18. Geis-Gerstorfer J. In vitro corrosion measurements of dental alloys. J Dent. 1994; 22:247-251.

19. Kidd E. The Disease and its Management. In: Kidd E, 3rd Edi Essentials of Dental Caries, Oxford UK: OUP Oxford; 2005.
20. Wahab FK, Shaini FJ, Morgano SM. The effect of thermocycling on microleakage of several commercially available composite Class V restorations in vitro. J Prosth Dent. 2003; 90:168-174.

21. Pazinatto FB, Campos BB, Costa LC, Atta Mt. Effect of the number of thermocycles on microleakage of resin composite restorations. Pesqui Odontol Bras. 2003; 17(4): 337-341

22. Masouras K, Silikas N, Watts DC. Correlation of filler content and elastic properties of resin-composites. Dent Mater. 2008; 24(7): 932-939.

23. Moorthy A, Hogg CH, Dowling AH, Grufferty BF, Benetti AR, Fleming GP. Cuspal Deflection and microleakage in premolar teeth restored with bulk-fill flowable resin-based composite base materials. J. Dent. 2012; 40(6):500-505.

24. Ilie N, Bucuta S, Draenert M. Bulk-fill resin-based composites: an in vitro assessment of their mechanical performance. Oper Dent, 2013; 38(6): 618-625.

25. Czasch P, Ilie N. In vitro comparison of mechanical properties and degree of cure of bulk fill composites. Clinic Oral Invest. 2013; 17(1): 227-235.

26. Garcia D, Yaman P, Dennison J, Neiva G. Polymerization Shrinkage and Depth of Cure of Bulk Fill Flowable Composite Resins. Oper Dent. 2014; 39(4):441-448.

27. Benetti AR, Havndrup-Pedersen C, Honore D, Pedersen MK, Pallesen U. Bulk-fill resin composites: polymerization contraction, depth of cures, and gap formation. Oper Dent. 2015; 40(2), 190-200.

28. Orłowski M, Tarczydło B, Chałas R. Evaluation of marginal integrity of four bulk-fill dental composite materials: in vitro study. Scient World J. 2015; Article ID 701262.

29. Bussadori SK, Guededs CC, Ram D. Chemo- mechanical Removal of caries in an Adolescent patient using a papain gel. J. Clin. Pediatric Dent. 2008; 32: 177-180.

30. Heintze S, Forjanic M and Cavalleri A. Microleakage of Class II restorations with different tracers - Comparison with SEM quantitative analysis. J Adh Dent. 2008; 10 : 259-267.

31. Goracci C, Sadek FT, Monticelli F, Cardoso PE, Ferrari M. Influence of substrate, shape, and thickness on microtensile specimens' structural integrity and their measured bond strengths. Dent Mater, 2004; 20: 643-654. 
32. Soares CJ, Soares PV, Santos-Filho PC, Armstrong SR. Microtensile specimen attachment and shape-finite element analysis. J. Dent. Res. 2008; 87: 89-93.

33. Ghassemieh E. Evaluation of sources of uncertainties in microtensile bond strength of dental adhesive system for different specimen geometries. Dent Mater. 2008; 24: 536-547.

34. Poitevin A, De Munck J, Van Landuyt K, Coutinho E, Peumans M, Lambrechts P. Critical analysis of the influence of different parameters on the microtensile bond strength of adhesives to dentin. J Adh Dent. 2008; 10:7-16.

35. Oznurhan F, Unal M, Kapdan A, Ozturk C. Flexural and microtensile bond strength of bulk fill materials. J Clin Pediat Dent. 2015; 39(3).
36. Al-Harbi F, Kaisarly D, Michna A, ArRejaie A, Bader D, El Gezawi M. Cervical interfacial bonding effectiveness of class II bulk versusincremental fill resin composite restorations. Oper Dent. 2015; 40-45.

37. Wang Y, Spencer P, Walker MP. Chemical profile of adhesive/ cariesaffected dentin interfaces using Raman micro spectroscopy. J Biomed Mater Res. 2007; 81(2): 279-286.

38. Nakajima M, Sano H, Urabe I, Tagami J, Pashley DH. Bond strengths of single-bottle dentin adhesives to cariesaffected dentin. Oper. Dent. 2000; 25: 2-10.

39. Erhardt MC, Rodrigues JA, Valentino TA, Ritter AV, Pimenta LA. In vitro micro TBS of one-bottle adhesive systems: sound versus Artificiallycreated caries-affected dentin. J Biomed Mater Res Appl Biomater. 2008; 86: 181-187 